\title{
Cosmopolitismo e Governança Transnacional Ambiental Uma Agenda Para o Desenvolvimento Sustentável
}

\author{
Paulo Márcio Cruz \\ Pós-doutor em Direito do Estado pela Universidade de \\ Alicante, na Espanha. Mestre em Instituições Jurídico- \\ -Políticas e doutor em Direito do Estado pela Universi- \\ dade Federal de Santa Catarina - UFSC. Coordenador e \\ professor do Programa de Pós-Graduação Stricto Sensu \\ em Ciência Jurídica da Universidade do Vale do Itajaí - \\ Univali em seus cursos de Doutorado e Mestrado em \\ Ciência Jurídica.pcruz@univali.br
}

\section{Zenildo Bodnar}

Graduação em Direito pela Universidade Estadual de Ponta Grossa (1998), Mestrado em Ciência Jurídica pela Universidade do Vale do Itajaí (2003). Mestrado em Urbanismo, História e Arquitetura da Cidade (PGAU - Cidade) pela UFSC na linha de pesquisa Meio Ambiente e Planejamento Urbano. Doutorado em Direito pela Universidade Federal de Santa Catarina (2005), Pós-Doutorado em Direito Ambiental na Universidade Federal de Santa Catarina e Pós-Doutorado em Direito Ambiental na Universidade de Alicante (Espanha). zenildo@univali.br.

\section{Resumo}

Neste artigo são analisados os desafios e perspectivas da governança transnacional ambiental a partir dos aportes teóricos sobre o cosmopolitismo, principalmente de Ulrich Beck. 0 artigo inicia-se com reflexões sobre os desafios globais da governança transnacional ambiental; prossegue com uma análise crítica do nacionalismo metodológico e é finalizado com reflexões sobre o cosmopolitismo e seus reflexos na governança global. A pesquisa constitui-se em um ensaio teórico, realizado a partir de pesquisa bibliográfica para a busca de subsídios aos argumentos de abordagem indutiva.

Palavras-chave: Cosmopolitismo. Estado Nacional. Governança transnacional ambiental. 


\title{
COSMOPOLITANISM AND TRANSNATIONAL ENVIRONMENTAL GOVERNANCE: AN AGENDA TO SUSTAINABLE DEVELOPMENT
}

\begin{abstract}
In this article will be analyzed the challenges and perspectives of transnational environmental governance based on theoretical contributions on cosmopolitanism, especially Ulrich Bech's. The article begins with reflections on the global challenges of transnational environmental governance; continues with a critical analysis of methodological nationalism and ends with reflections on cosmopolitanism as a global governance strategy. The research is a theoretical essay, carried out from literature to search subsidies inductive approach arguments.
\end{abstract}

Keywords: Cosmopolitanism. National State. Transnational environmental governance.

\section{Sumário}

1. Introdução. 2 Desafios Globais da Governança Transnacional Ambiental. 3 Análise Crítica do Nacionalismo Metodológico e os Reflexos do Cosmopolitismo na Governança Transnacional. 4 Referências. 


\section{INTRODUÇÃO}

O propósito deste artigo é fazer uma reflexão crítica sobre os desafios da governança ambiental a partir da ideia-chave do cosmopolitismo de Beck. O enfoque será necessariamente interdisciplinar e utilizará como ilustração a recente Convenção do Clima de Paris 2015 e os objetivos e metas para o desenvolvimento sustentável da ONU para 2030.

O objetivo geral é evidenciar os limites das estratégias de governança empreendidas a partir de estruturas normativas e instituições locais para a proteção de um bem jurídico (meio ambiente) que é espacialmente planetário e enaltecer a importância de novos arranjos institucionais e de marcos normativos para uma governança transnacional.

Apesar da falta de uniformidade conceitual para a categoria cosmopolitismo e a partir da sua dimensão necessariamente interdisciplinar, entende-se como uma resultante da dinâmica da alta modernidade, um processo relativamente objetivo e que independe da vontade das pessoas envolvidas. Nesta perspectiva, difere de cosmopolitização (sentido filosófico e normativo) e de cosmopolitanismo enquanto posição normativa já assumida por diversos intelectuais, conceito mais estático (Guivant, 2015). Cosmopolitanismo seria uma forma de cosmopolitismo reflexivo ou qualificado. Não apenas uma ideia falada, mas como afirmam Beck e Grande (2010) um "símbolo ou ritual" que produz Filosofia em identidade pessoal e social com relevante contribuição para a análise social e para a "militância”/engajamento dos cidadãos. Cosmopolitanismo era um conceito que ainda estava sendo desenvolvido por Beck.

Neste estudo o que se destacará é a intensa relação e a repercussão do cosmopolitismo, enquanto processo dinâmico e irreversível, na governança transnacional ambiental. 
O problema central que se apresenta é se os riscos transnacionais que ameaçam o futuro do planeta, inclusive na perspectiva existencial e, a partir de forte pressão do "imperativo cosmopolita", podem gerar união entre os povos e possibilidades de ação cooperativa e em rede enquanto estratégia de governança transnacional.

Para o alcance dos objetivos o artigo foi estruturado da seguinte forma: inicialmente são aportadas reflexões sobre os desafios globais da governança transnacional, com ênfase na temática ambiental; em seguida é feita uma análise crítica do nacionalismo metodológico para pautas espacialmente transnacionais; ao final aborda-se o cosmopolitismo e seus reflexos na governança global para a construção da sustentabilidade,${ }^{1}$ com alusão exemplificativa da recente Convenção do Clima de Paris 2015 e os objetivos e metas para o desenvolvimento sustentável da ONU.

\section{DESAFIOS GLOBAIS DA GOVERNANÇA TRANSNACIONAL AMBIENTAL}

Temas globais geram problemas e desafios também com escala ampliada de complexidade. Nos temas do ambiente, que possui vocação espacialmente transnacional, isso ocorre até de forma mais acentuada, pois os interesses gravitam também numa perspectiva ampliada no que diz respeito aos sujeitos, futuras gerações e toda comunidade de vida.

Os riscos globais, potencializados por eventos naturais extremos das últimas décadas e pela revolução tecnológica, incentivam novos pactos e estratégias de governança para a construção de uma nova civilidade global baseada eticamente na cooperação.

${ }^{1}$ Sobre o papel da categoria sustentabilidade para os autores do presente artigo, recomenda-se a leitura de Cruz e Bodnar, 2012, p. 251-570. 
O meio ambiente apresenta titularidade difusa e vocação espacialmente planetária e requer estratégias também globais de defesa e proteção. Martín Mateo (1997, p. 58) observa que é exatamente a disposição institucional em parcelar a terra em Estados soberanos que inviabiliza o estabelecimento de uma ordem mundial coerente para sistemas naturais intrinsecamente planetários.

Nessa mesma perspectiva é a conclusão de Silvia Jaquenod (2008, p. 207) ao defender a necessidade de novos limites geopolíticos para a governança dos recursos naturais, enfatizando que a posição baseada na cooperação e no compartilhamento supera a situação real entre Estados.

A crise ecológica, além de ser espacialmente global, não significa apenas o descompasso entre a geração de bens e serviços ambientais e a sua utilização antrópica. É na verdade a crise da própria civilização contemporânea. $\mathrm{O}$ modo de organização política não é mais adequado para as novas demandas transnacionais (Cruz; Bodnar, 2011, p. 221-232).

O Direito, enquanto estratégia de gestão de conflitos e de articulação da solidariedade, ${ }^{2}$ também está fracassando por não fomentar a melhora contínua nas relações entre os seres humanos e a natureza, fato este que potencializa o aumento da crise de valores, que é também cultural e espiritual.

No plano da produção do conhecimento, também é indispensável a necessária aproximação entre as Ciências Naturais e Sociais em prestígio da interdisciplinaridade.

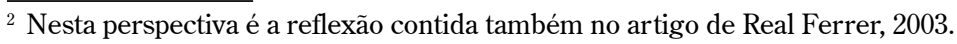


Este quadro impõe que urgentemente sejam repensadas e reconfiguradas as estruturas políticas, as instituições e o próprio Direito, que não pode ser apenas uma técnica simplória de controle social, ou dito de forma clara, de comando e controle, pois deve também estimular e inclusive premiar condutas positivas. ${ }^{3}$

As profundas alterações ocorridas nos últimos tempos, e ainda em contínua e progressiva marcha, contribuíram para o agravamento dos problemas sociais e ambientais, gerando múltiplas e complexas situações de injustiça socioambiental e demandas por instrumentos de governança.

O enfrentamento da crise/carência global de governança sugere, dentre outras medidas: enfoque interdisciplinar, holístico, sistêmico e integrado; cidadania planetária com intensa e qualificada participação e controle social; solidez institucional; instrumentos legais efetivos e cogentes; fortalecimento de capacidades e profissionalização; intercâmbio de informações e de mecanismos de controles e compartilhamento solidário de custos e principalmente de benefícios.

O ponto de partida para este câmbio imprescindível é a necessidade de uma forte consciência geral impulsiva ${ }^{4}$ que desencadeie novas atitudes cooperativas e solidárias em escala global. O exercício substancial de uma cidadania transnacional é fundamental para mudanças duradouras e consequentes. Necessita-se do fortalecimento dos espaços públicos e de controle social especialmente qualificado e amplo, ou seja, de uma democracia também transnacional para conduzir e reorientar práticas e ações impostas apenas para atender à lógica de mercado dominante.

${ }^{3}$ Esta foi também a conclusão exposta no artigo de Cruz, Bodnar, 2011. p. 221-232.

${ }^{4}$ Expressão reiteradamente utilizada por Ulrich Beck em seus últimos escritos e conferências. 


\section{ANÁLISE CRÍTICA DO NACIONALISMO METODOLÓGICO E OS REFLEXOS DO COSMOPOLITISMO NA GOVERNANÇA TRANSNACIONAL}

A ideia de Estado, na sua concepção moderna e também como instância de governança, apesar de ainda necessária, está claramente defasada para os novos desafios, pois as razões e causas históricas que motivaram o seu surgimento sofreram contundente câmbio.

Ao abordar o tema da formação das nações, enquanto elemento constituidor dos Estados, Maurice Hariou (2003, p. 35-36) as define como: grupos de população fixados ao solo, unidos por um laço de parentesco espiritual que envolve o pensamento da unidade do mesmo grupo. Explica que o vínculo de parentesco espiritual não diz respeito a crenças, mas sim à forma de pensar, agir, em suma, a mesma mentalidade. Destaca também o pensamento e a vontade atual de unidade nacional como elemento imprescindível para caracterizar uma nação. E acrescenta que o sentimento que anima cada coração é o amor deste meio nacional que se chama pátria.

Esta concepção, baseada no que o autor chama de parentesco espiritual, não é mais suficiente para sedimentar vínculos eticamente duradouros e a imprescindível sensação de pertencimento a uma única morada pela qual todos são responsáveis e da qual depende necessariamente o destino comum.

As grandes causas nacionais, historicamente defendidas, justificaram inclusive a eclosão de guerras mundiais, e hoje nem sempre aparecem com propósitos eticamente sustentáveis, tendo em vista os propósitos não tão nobres de determinados líderes locais.

Ocorre a conquista de novos territórios com o sacrifício de múltiplos direitos humanos, bem como a dominação e imposição de culturas. Nesta perspectiva é a reflexão crítica efetivada por Spivak (2010, p. 59) a 
partir de uma análise exemplificada dos subalternos com ênfase no papel da mulher hindu, ao discorrer que há "um desvio de ideal - o povo ou subalternos - os quais são definidos como uma diferença da elite.” Ou seja, há uma disparidade nos sujeitos inseridos no contexto social, em que a sociedade caracteriza e distingue grupos e vítimas, restringindo seu papel e voz social, o que caracteriza o contexto social e cultural marcado pelo silêncio de alguns, pois as vítimas sociais, ou como diria Spivak (2010, p. 126), “os subalternos não podem falar”. Tais contribuições trazem a essência dos efeitos do colonialismo e pós-moderno capitalista.

Conquista de territórios e imposição de culturas são projetos que devem ser repudiados no atual desenvolvimento da civilização. Afinal, de que valem as glórias comuns do passado se não há um propósito ético nobre e grandioso com o futuro? A maturidade civilizatória deve ser dimensionada pelo grau de comprometimento com a garantia dos direitos humanos, com a consolidação da paz e da sustentabilidade. Estas sim devem ser as grandes causas das nações transnacionalizadas.

A sensação de pertencimento de todos os cidadãos do planeta é e deve ser mundial. Trata-se de um apelo à cooperação e à solidariedade em todos os níveis e dimensões, para que sejam superadas as formas individualistas de viver, de conceber e perceber o próximo e de agir dos Estados, empresas e instituições, baseados em princípios e valores individualistas.

Na busca do ideário da "paz perpétua”, fundada na razão e na inteligência humanas, Kant já sugeria a formação de uma liga de povos, que não seria o mesmo que um superestado envolvendo povos e territórios, pois no seu entendimento cada Estado tem e deve conservar a sua individualidade. A liga de povos resultaria de um contrato mútuo entre Estados livres, aliados por objetivos e compromissos comuns e seria fundamentada num "Direito Cosmopolita”. O direito de visita e de hospitalidade promoveriam a comunicação e o relacionamento pacífico entre pessoas dos mais variados pontos do mundo, e contribuiriam para transformar 
em realidade o ideal de uma "constituição cosmopolita”. Enfatizava que esse desejo não era mera fantasia, "mas um complemento necessário do código não escrito tanto do direito de Estado como do direito das gentes para um direito público dos homens em geral e, assim, para a paz perpétua [...]" (Kant, 1989).

A ideia de uma comunidade cosmopolita não é recente, porém não pode ser um projeto impositivo de um saber ou de uma cultura dominante, pois qualquer projeto consequente de reconfiguração das esferas políticas e jurídicas - não necessariamente na forma de comunidade única - deve corresponder aos anseios mais legítimos de todas as nações e que efetivamente caracterize uma pauta axiológica de consenso de todos os povos.

A nova ordem mundial, influenciada por diversos fatores decorrentes da intensificação do fenômeno da globalização, torna oportuna e necessária a discussão sobre a organização de espaços públicos transnacionais que viabilizem a democratização das relações entre Estados, relação esta fundada na cooperação e solidariedade com o intuito de assegurar a construção das bases e estratégias para a governança transnacional (Cruz; Bodnar, 2013, p. 9-30).

Santos (2005) aborda o tema da globalização política e do Estado-Nação, refletindo sobre a internacionalização deste na modificação dos poderes estatais, considerando a possibilidade de se fazer de uma federação mundial para resolução das lides globais, anunciando a necessidade de novas instâncias de governança e o fenecimento do modelo estatal.

Arranjos institucionais idealizados para a modernidade já não são suficientes para o atual momento histórico. Até a Primeira Guerra Mundial os Estados desempenhavam um papel formal, passivo e meramente de abstenção, pois as Constituições apenas proclamavam os direitos individuais clássicos de primeira dimensão que eram exercidos, como regra, diretamente pelos cidadãos. As esferas econômicas e sociais se regulavam por si mesmas. Esse fator supôs a existência de um consenso de base ideo- 
lógica por parte dos grupos que formavam a opinião pública e controlavam todos os meios de comunicação da sociedade, consenso este baseado no paradigma da liberdade.

Com a evolução da sociedade, todavia, este modelo estatal revelou-se incapaz para atender às recentes demandas da nova ordem social massificada e hipercomplexa. Com isso foi fundamental uma mudança contundente de atitude e função, pois se no Estado liberal a estratégia de ação era não interferir para resguardar os direitos liberais (liberdade, propriedade, dentre outros), no Estado social passou-se a requerer uma atitude positiva para que a garantia plena dos direitos aconteça também por intermédio do Estado, que passou a ser responsável por uma grande quantidade de prestações sociais, como saúde, educação, segurança pública.

No contexto da sociedade de risco, hipercomplexa e policonflitiva, a relação entre o Estado e a sociedade deve ser de parceria e cooperação. Com o surgimento dos novos direitos de terceira dimensão, em especial o direito ao meio ambiente sadio e equilibrado, impõe-se uma redefinição do modo de organização política estatal. O Estado passa a não mais atuar apenas como garantidor dos direitos de liberdade e provedor de direitos sociais, mas precisa agir em conjunto com a sociedade para assegurar, inclusive para as futuras gerações e para toda a comunidade de vida, condições ideais de habitabilidade.

Assim, é oportuno que novas propostas teóricas sejam discutidas na direção de um novo sistema político global que não esteja a serviço do mercado global.

Um novo conjunto teórico com relação ao poder público poderia estruturar-se em torno de quatro grandes objetivos: $1^{0}$ - a organização do desarmamento mundial para níveis que não ameacem a existência da vida no planeta; $2^{-}$- a organização do acesso aos recursos naturais do planeta de maneira igualitária e rigidamente sob os princípios do desenvolvimento sustentado, de modo a diminuir gradativamente as desigualdades; $3^{0}-\mathrm{a}$ 
negociação de relações econômicas abertas e flexíveis entre as principais regiões do mundo, que na atualidade encontram-se desigualmente desenvolvidas (Häberle, 2007, p. 56) e $4^{\mathrm{0}}$ - o início de negociações para a correta gestão da dialética mundial/nacional nas áreas das comunicações, cultura e política. Pode-se pensar inclusive em gestão da distribuição de competências entre o plano transnacional e os planos regionais e nacionais.

Dito de outro modo, o que é realmente importante na configuração de um novo conjunto teórico sobre o tema é a democracia como valor de civilização e não o Estado.

Deve-se voltar, porém, à questão sobre qual será o futuro do Estado! Nesse sentido pode-se refletir sobre três possibilidades. A primeira delas seria a volta de um Estado forte e autônomo, capaz de manter o controle do poder perante os novos organismos e entes transnacionais. Esta é uma alternativa pouco realista pelas razões já indicadas em outras partes deste artigo. Cabe uma segunda possibilidade, que consistiria em confiar na capacidade autorregulatória do emergente sistema global e reduzir, em consequência, a presença e ação dos Estados até que sejam reduzidos a meros coadjuvantes de uma sociedade em rede, multicêntrica e com poderes compartilhados em diversos níveis. É uma alternativa não só possível, mas também realista, considerando o cenário mundial atual e suas projeções. O problema está em que se trata de uma alternativa demasiado realista e, portanto, extraordinariamente perigosa. A referência é à confusão usual entre mundialização e neoliberalismo ou, se se preferir, à distinção entre a ideia da globalização assentada no dogma de que toda atividade humana atual deve estar sujeita ao primado da economia global.

Outra coisa, bem diferente, é a globalidade, ou seja, a existência de uma sociedade mundial multidimensional, policêntrica, contingente e política, capaz de resolver de modo aceitável os grandes desafios de sustentabilidade sociais, econômicos, políticos e ambientais que o mundo atual enfrenta. 
Diante destas duas alternativas extremas, cabe uma posição intermediária, embasada na construção teórica de um Estado adaptado à nova situação. Uma alternativa que permitisse a vigência de um poder público estatal, mas construído com base na nova realidade mundial e capaz de ser uma peça na engrenagem pública global.

O novo Estado estaria encaixado numa rede de compartilhamento de funções públicas, interagindo com as organizações transnacionais, tanto governamentais como não governamentais, por um lado, e com as regiões, comunidades, Estados federados e entidades locais, por outro. Um novo Estado que tenha como paradigma a sustentabilidade (Cruz; Real Ferrer, 2015, p. 239).

Em outras palavras, os novos estados exerceriam sua atividade não como entidade soberana, mas como parte componente de uma ordem política internacional mais ampla e complexa (Cruz, 2010, p. 22-41). Assim, o Estado tende a se extinguir como estrutura de soberania - um dos motivos para a superação do Estado Constitucional Moderno - e como coordenador de uma hierarquia piramidal (Ferrajoli, 2002). O novo Estado não seria mais um pretenso gestor de uma hierarquia soberana, mas sim um potencial negociador e integrador de sua comunidade no concerto transnacional.

A criação de instituições intermediárias, capazes de não só assegurar a necessária transparência, mas também um grau mínimo de legitimidade é, portanto, essencial. Isso supõe que, no lugar de se imaginar uma “comunidade mundial”, que seria resultado direto da eleição de milhões de indivíduos abstratos, se está trabalhando na construção de uma comunidade de comunidades, estabelecida sobre a base da negociação. E entre diferentes comunidades políticas que compartilham os mesmos princípios comuns, fazendo-as compatíveis entre si e substituindo o conflito pela cooperação e o enfrentamento entre soberanias pela autonomia e independência organizadas (Habermas, 2006, p. 158). 
Isto está proposto assim porque pressupõe a criação de instituições políticas de intermediação, capazes de levar em consideração as duas lógicas, tanto a da concentração do poder quanto a da descentralização. E de organizar, por conta da mediação das instituições políticas, a passagem da primeira para a segunda, o que é talvez a principal tarefa política na pós-modernidade. O futuro da humanidade talvez dependa muito disso.

Neste quadrante é que a crítica teórica ao nacionalismo metodológico, entabulada por Ulrich Beck, desponta como de extrema importância, pois denuncia claramente os limites da concepção de Estado-Nação para a gestão do risco global (Beck; Sznaider, 2006).

A crítica ao nacionalismo metodológico naturalmente não prega o fim do Estado, mas enfatiza a ideia de que a organização nacional, como um princípio estruturante da sociedade e da ação política, não pode mais servir como ponto de referência de orientação para o desenvolvimento social do observador científico.

Estes autores (Beck; Sznaider, 2006) explicam os desvios epistemológicos ocasionados nas Ciências Sociais pelo nacionalismo metodológico, especialmente por equiparar as sociedades com as sociedades do Estado-Nação, ${ }^{5}$ empreendendo um foco de análise simplista e reducionista apenas no Estado enquanto categoria fundamental da ciência política e no seu governo, como se o mundo das Ciências Sociais estivesse restrito aos confins das bordas do Estado-Nação.

\footnotetext{
${ }^{5}$ A expressão Estado-Nação, utilizada por Beck, é entendida pelos autores do presente artigo como Estado Constitucional moderno. O Estado-Nação, ou Estado Constitucional Moderno, foi o modelo mais difundido depois da Segunda Guerra Mundial. O aumento do número de Estados e o crescente peso relativo das burocracias nas sociedades industriais avançadas tiveram uma grande influência na definição da política e de seu objeto de estudo, que passou a ser, principalmente, o poder do Estado.
} 
Ocorre que os fenômenos sociais, com intensas repercussões nas esferas política e econômica, são muito mais abrangentes e complexos. Conforme Beck, hoje a produção social da riqueza está associada à produção de riscos. Na modernidade ocorreu uma mudança da lógica da divisão da natureza para a lógica da divisão dos riscos. Esse câmbio ficou vinculado a duas condições: redução e exclusão da miséria material e crescimento livre dos riscos. Os riscos enquanto "produto global da maquinaria do progresso industrial" formam uma simbiose entre as ciências da natureza e as ciências do espírito, entre racionalidade cotidiana e racionalidade dos especialistas, entre interesses e feitos, rompendo a racionalidade das ciências de averiguar objetivamente as causas e consequências. O próprio efeito social das definições de risco não depende de sua consistência científica.

O tema do risco une âmbitos e conclama para uma nova política transnacional e, por consequência, novas formas de governança, que impõem um urgente repensar da relação entre natureza e sociedade diante da dinâmica social e política de desenvolvimento histórico sem precedentes. Esta política requer a superação da metodologia do Estado-Nação e uma "guinada cosmopolita" na teoria social e política a partir do cosmopolitismo metodológico.

Nessa perspectiva, o cosmopolitismo metodológico refere-se a uma abordagem que considere as várias modernidades (diferentes em cada sociedade) e interdependências globais (modernidades reflexivas) para fazer uma reflexão teórica e pesquisa empírica. Esta "guinada cosmopolita" deve contemplar: ferramentas conceituais para uma teoria da modernização; desconstrução da modernidade ocidental; abordagem do problema e análise; reflexões de uma teoria da modernidade cosmopolita enfocando a agência política e as perspectivas de realização. 
Como possível resposta às insuficiências e à clara defasagem histórica do nacionalismo metodológico, debate-se a emergência do cosmopolitismo metodológico, com a ousada proposta de revolucionar o nível de análise da sociologia tradicional e confrontá-la com a realidade que opera na borda do Estado-nação.

Conforme advertem Szerszynski e Urry (2006), o cosmopolitismo não deve ser igualado com o global (ou globalização, ou globalismo), com "teoria do sistema mundial”, com "política mundial”, ou com "mundo da sociedade”. Todos esses conceitos pressupõem dualismos básicos, tais como doméstica/estrangeira ou nacional/internacional, e que, na realidade, tornaram-se ambíguos. O cosmopolitismo metodológico abre novos horizontes, demonstrando como se pode fazer a investigação empírica das passagens fronteiriças e outros fenômenos transnacionais possíveis.

Afinal, é na borda dos confins do Estado-Nação que muitos temas de dimensão transnacional como a temática do ambiente surgem de forma desafiante, destacadamente no que diz respeito às estratégias de boa governança.

A busca por mais cooperação entre os povos e formas eficazes de governança tem sido uma constante nas últimas décadas, inclusive foi um dos principais temas da Rio +20 , que contou basicamente com três propostas: a primeira foi a de criar um novo organismo na ONU específico para a área ambiental; a segunda foi de dar ao Programa das Nações Unidas Para o Meio Ambiente (Pnuma) um novo status, igualando-o a organismos como a Organização Mundial do Comércio (OMC). A terceira proposta foi a de se promover a elevação do poder da Comissão de Desenvolvimento Sustentável da ONU.

A pauta da governança transnacional ambiental continuou também na COP-21 (conferência do clima da ONU), ocorrida no final de 2015 em Paris e que, após duas semanas de intensas negociações, resultou num acordo histórico abrangente para a redução de emissão de carbono obje- 
tivando diminuir o aquecimento global. Este acordo pode ser considerado um marco positivo na perspectiva da governança, pois foi ratificado por 195 países-membros da Convenção do Clima da ONU e a União Europeia. Um dos pontos mais importantes do acordo e que potencializa o sucesso da sua efetivação diz respeito à forma de financiamento. ${ }^{6}$ Apesar dos avanços, vários autores também criticam o acordo por entender que este não será efetivo no atual modelo econômico, a exemplo de Leonardo Boff, que afirma que os negociadores e chefes de Estado “[...] simplesmente não pensam no destino comum. Só dão asas à fúria produtivista, mercantilista e consumista, pois esse é o mainstream globalizado” (Boff, 2015).

O tema da governança transnacional ambiental também aparece em destaque na agenda 2030 da ONU, destacadamente no objetivo 16 estatuído nos seguintes termos: "16. Promover sociedades pacíficas e inclusivas para o desenvolvimento sustentável, proporcionar o acesso à justiça para todos e construir instituições eficazes, responsáveis e inclusivas em todos os níveis”. A partir deste objetivo geral foram traçadas metas específicas e dentre elas consta:

16.6 Desenvolver instituições eficazes, responsáveis e transparentes em todos os níveis; 16.7 Garantir a tomada de decisão responsiva, inclusiva, participativa e representativa em todos os níveis; 16.8 Ampliar e fortalecer a participação dos países em desenvolvimento nas instituições de governança global.

O alcance destes objetivos e metas dependerá necessariamente da observância e atenção aos imperativos cosmopolitas, tanto na produção qualificada do conhecimento como nas estratégias de mobilização e parcerias entre os povos.

${ }^{6}$ Ficou acordado que os países desenvolvidos irão aplicar US\$ 100 bilhões por ano em medidas de combate à mudança do clima e adaptação em países em desenvolvimento. 
Apesar do cenário relativamente sombrio que se desenha, também é certo que um dos efeitos mais destacados da sociedade de risco global é o mobilizador. Afinal, a propulsão de novas estratégias de governança depende da persuasão geral acerca da efetiva necessidade de mudanças profundas. Assim, é possível afirmar que subjaz uma força motriz na sociedade de risco global que gera efeitos mobilizadores com repercussão direta na organização social, política e também na produção do conhecimento.

Na perspectiva do cosmopolitismo, o futuro exige a consolidação de novas formas de governança, estruturadas como uma grande teia de proteção do planeta, regidas por princípios ecológico-sociais e que assegurem alternativas e oportunidades democráticas mais inclusivas, participativas e emancipatórias e tenham como preocupação garantir um mundo melhor para as futuras gerações. Somente com novas estratégias globais de governança, baseadas na cooperação e na solidariedade ancoradas epistemologicamente na interdisciplinaridade é que será possível assegurar um futuro com sustentabilidade e mais justiça.

Assim, conclui-se que é necessário não só desembalar o cosmopolitismo para as Ciências Sociais, como também para os temas essenciais da governança transnacional ambiental.

\section{REFERÊNCIAS}

BECK, U.; GRANDE, E. Varieties of second modernity: The "cosmopolitan turn" in social and political theory and research. The British Journal of Sociology. Londres, n. 61, p. 409-443, 2010.

BECK, U.; SZNAIDER, N. Unpacking cosmopolitanism for the social sciences: a research agenda. The British Journal of Sociology. Londres, v. 57, n. 1, 2006. 
BOFF, L. A COP 21 pavimenta o caminho para o desastre. Entrevista publicada em 21.12.2015 no Jornal do Brasil. Disponível em: <http://www.jb.com. br/leonardo-boff/noticias/2015/12/21/a-cop-21-pavimenta-o-caminho-para-o-desastre/?from_rss=rio $>$. Acesso em: 12 jan. 2016.

CRUZ, P. M.; REAL FERRER, G. Direito, sustentabilidade e a premissa tecnológica como ampliação de seus fundamentos. Sequência (UFSC), Florianópolis, v. 36, n. 71, p. 239-278, dez. 2015.

CRUZ, P. M. Repensar a democracia. Revista da Faculdade de Direito da UFG, Goiânia, v. 33, n. 1, p. 22-41, 2010.

CRUZ, P. M.; BODNAR, Z. Gobernabilidad transnacional ambiental en Río +20. Juridicas, Manizales - Colombia, v. 10, n. 2, p. 9-30, 2013.

CRUZ, P. M.; BODNAR, Z. Transnacionalización, Sostenibilidad y el Nuevo Paradigma del Derecho en el Siglo XXI. Iuris Tantum, México, v. 5, n. 1, p. 251-270, 2012.

CRUZ, P. M.; BODNAR, Z. El Clima Como Necesidad de Gobernanza Transnacional: Reflexiones Póst-Copenhagen 2009. Revista Aranzadi de Derecho Ambiental, Barcelona, Espanha, v. 19, n. 2, p. 221-232, 2011.

FERRAJOLI, L. A soberania no mundo moderno: nascimento e crise do estado nacional. Tradução Carlo Cocciolo e Márcio Lauria Filho. São Paulo: Martins Fontes, 2002.

GUIVANT, J. Aula ministrada no Programa de Doutorado Interdisciplinar em Ciências Humanas. Florianópolis: UFSC, SC. 2015.

HÄBERLE, P. Estado constitucional cooperativo. Tradução Marcos Augusto Maliska e Elisete Antoniuk. Rio de Janeiro: Renovar, 2007.

HABERMAS, J. O ocidente dividido. Tradução de Luciana Villas-Bôas. Rio de Janeiro: Tempo Brasileiro, 2006.

HARIOU, M. Princípios del Derecho Público y Constitucional. Trad. Estudio preliminar, Notas y Adiciones: Carlos Ruiz del Castillo. Granada: Camares, 2003.

JAQUENOD, Silvia. Derecho ambiental. 2. ed. Madrid: Dykinson, 2008. 
KANT, I. À paz perpétua. Porto Alegre: L\&PM, 1989.

MARTÍN MATEO, R. Tratado de Derecho ambiental: recursos naturales. Madrid: Trivium, 1997. V. III.

ORGANIZAÇÃO DAS NAÇÕES UNIDAS. ONU. Metas 2030: novos objetivos de desenvolvimento sustentável. Disponível em: $<$ http://www.unmultimedia. org/radio/portuguese/conheça-os-novos-objetivos-de-desenvolvimento-sustentável/>. Acesso em: 15 jan. 2016.

REAL FERRER, G. La solidariedad en el derecho administrativo. Revista de Administración Pública (RAP), Madrid, v. 1, n. 161, mayo/ago. 2003.

SANTOS, B. de S. Os processos da globalização. In: SANTOS, B. de S. (Org.). A globalização e as ciências sociais. 3. ed. São Paulo: Cortez Ed., 2005.

SPIVAK, G. C. Pode o subalterno falar? Belo Horizonte: Editora UFMG, 2010. SZERSZYNSKI, B.; URRY, J. Visuality, mobility and the cosmopolitan: inhabiting the world from afar. The British Journal of Sociology, Londres, v. 57, n. $1,2006$.

ZSÖGÖN, S. J. de. Derecho ambiental, sistemas naturales y jurídicos. Barcelona: Dycinson, 2008.

Recebido em: 8/2/2016

Aceito em: $30 / 5 / 2016$ 